\title{
Academic Social Networks: How the web is changing our way to make and communicate researches
}

\author{
Giovanni Bonaiuti
}

University of Cagliari, Italy,g.bonaiuti@unica.it, ORCID 0000-0003-0219-3603

\begin{abstract}
Networking is not only essential for success in academia, but it should also be seen as a natural component of the scholarly profession. Research is typically not a purely individualistic enterprise. Academic social network sites give researchers the ability to publicise their research outputs and connect with each other. This work aims to investigate the use done by Italian scholars of 11/D2 scientific field. The picture presented shows a realistic insight into the Italian situation, although since the phenomenon is in rapid evolution results are not stable and generalizable.
\end{abstract}

Keywords: Academic social network sites; Research strategies; Altmetrics; Scholars visibility

\section{Introduction}

Internet is changing the way we search, communicate, share information and connect with each other. It is no longer necessary to go out and spend time in library stacks; much of the information needed is available directly on our own desks. Information technology has sped up the time of publication and made it possible to access almost in real time - papers and researches made all round the world. Furthermore, transition from the print to the electronic format has increased the number of scientific publications thanks to reduction in printing and distribution costs. Bornmann and Mutz (2014) suggest that the rate of global scientific output growth is closer to $8-9 \%$ each year, which equates to doubling every nine years. New models of scholarly communication have emerged that enhance and challenge the established systems (Mabe, 2010). Alongside the traditional publishers, today it has increased the number of universities that have their own 'university press' and a significant phenomenon is represented by open access worldwide movement that aim to give free availability to online reading materials according to the principles of open knowledge1. Moreover, Internet has facilitated publishing and archiving, plumping 'self-publishing practice' in which authors themselves make a copy of their works and ideas directly online; phenomenon that is boosted by the advent of social media, like blogs, Facebook or Twitter. One consequence of that could be seen in the increase of quotes and citations from Web resources also in humanities and social sciences papers (Yang, Qiu, \& Xiong, 2010). Alongside opportunities, growth in scientific production has triggered difficulties in finding and selecting influential papers. No researcher can read everything that may be of potential interest for his or her work. A choice must be made and, conceivably, the choice is to select what is most visible or easily available. On the other side, for authors, it is even more difficult to stand out and enforce their work. In other words, researchers are today faced with two problems: being able to select the most important papers to be used as the basis for their researches and, simultaneously, finding out ways to increase the likelihood that his or her works are noticed. An answer given by information industries in

\footnotetext{
${ }^{1}$ Detailed definitions of the Open Access initiative are to be found in the firsts meetings final declarations: Budapest 2002 (http://www.budapestopenaccessinitiative.org/read), Bethesda 2003 (http://www.earlham.edu/ peters/fos/bethesda.htm), Berlin 2003 (http://openaccess.mpg.de/Berlin-Declaration).
} 
support to scientific visibility is represented by a series of indexes based on statistical analysis of quantitative data, used to provide a ranking to resources and to indicate the relative importance of a journal - as well as a scholar - within its field. Well-known metrics, like h-index and g-index for authors or impact factor for journals, are based on citations received by articles in a period of time. Works highly cited deemed to be more important than those with lower number of citations. Given that citations confer recognition on the cited author and that this credit is important for academic careers and evaluations (Moed, 2005), authors and institutions should benefit from making their publications easier to find and access (Thelwall \& Kousha, 2014). The use of these indexes, or 'bibliometrics', starts in the second half of the last century, but despite the heated debate and criticism about their use, still represents a criterion for evaluating the work of researchers 2.

Up to now, the visibility of an article, and therefore its chance of being cited, has been closely linked to the prestige of the journal. The increase in the number of scientific sources and, primarily, the advent of information network technologies is quickly changing the scenario. In the Web 2.0 era, social media have provided new cues to give visibility to scholars' work. In particular, academic social media platforms allow users to tag, annotate, bookmark and rate scientific literature. Therefore, sites that collect and share information on scientific content can provide alternative ways capable of outperforming traditional citation-based impact measures, in terms of coverage, speed and efficiency. A sign of this change is represented by the increased use of social media gadgets that link journal Web sites to Facebook, Twitter and blogs. Scientific journals and social media tools have two characteristics in common: they are means for publishing information and for paying attention to somebody's work (Kortelainen \& Katvala, 2012). Another footprint is given by the rise of alternative metrics, known as 'altmetrics', that aim to cover not just citation counts, but also other aspects of the impact of a work, such as how many data and knowledge bases refer to it, article views, downloads or mentions in social media and news media (Galligan \& Dyas-Correia, 2013; Liu \& Adie, 2013). Alt-metrics have not yet relevance on the academic careers, but they can tell a lot about how papers and ideas are accepted. Social media offer a powerful way for researchers to boost their professional profile and act as a public voice for science. Thus, it is not only that scientist can use social media to communicate their research, but that they must use them (Van Eperen \& Marincola, 2011). It is documented that this trend is in place, namely that researchers are increasingly using social media as a way to share journal articles, advertise their thoughts and scientific opinions, post updates from conferences and meetings and circulate information about professional opportunities and upcoming events (Bik \& Goldstein, 2013).

This paper aims to investigate the phenomenon in a specific context: that of Italian scholars engaged in educational research. The goal is to figure out whether Academic Social Network Sites are known and utilized, and what are the characteristics of the main users. The work will analyze the use of these systems by faculty involved in a specific area of research: those who are dealing with didactic and educational research. To do this the research will use a database of scholars provided by the Ministry of Education and, for each name there will be established the presence inside the principal social network sites.

\section{Theoretical framework}

A main step of every research in education is the literature review. A thorough knowledge of related literature is important for both quantitative and qualitative studies to identify and evaluate relevant articles to be cited and used as landmark of any new works (Ary, Jacobs \& Sorensen, 2009). Researches previously carried out are the starting point from which to proceed towards new findings. However, it is tough to identify all articles relevant to a given project, even if following a systematic literature search method, and so scholars use a finite set of searches and other methods in order to identify relevant researches (Thelwall \& Kousha, 2015; Haines et al, 2010; Niu et al., 2010). According to Haines and colleagues (2010), researchers use a variety of information resources ranging from popular Internet search engines to specific databases. The aim is generally to identify more papers as possible using a set of keywords, in the hope of not missing relevant ones. Scholars usually use a finite set of searches and other methods in order to identify relevant works, unlike what routinely occurs in the development of systematic reviews or meta-analyses. In the literature research activities, scientific databases like SCOPUS, PubMed or PsycInfo, are used in conjunction with 'web-oriented' search engines like GoogleScholar since it offers results comparable to expensive commercial tools, if not better (Falagas et al., 2008; Walters, 2011). The goal is to gather as much information as possible, ensuring that the relevance will be greater than the

\footnotetext{
${ }^{2}$ In Asia, America or Europe, the research evaluation and management of funds, depends on indicators such as papers published in academic journals that belong to the database Science Citation Index (SCI) for the hard sciences and Social Sciences Citation Index (SSCI) for the social sciences. In our country, although between heated controversy, bibliometric is gradually spreading following the university reform (L.240/2010) that introduced the national scientific qualification procedure (ASN) to function as professor in Italian Universities and the Quality Research Assessment (VQR) that aim to evaluate the results of scientific research of universities and research institutions.
} 
quantities. Habitually, the researchers obtain further information analysing references of search results or relying on previous investigations and literature scanning. Almost certainly, there are privileged papers closer to the 'central object' and excluded papers for which it is difficult to obtain full-text copies, particularly if they are similar to other articles that are more easily available.

Researchers in the field of humanities and social sciences rely even on book chapters that, in some case, are not extensively indexed by search engine. Furthermore, in non-English-speaking countries the matter is even more complex. In Italy, for example, only small parts of national scientific journals are indexed by specialised databases such as ERIC, MedLine or SCOPUS. For an Italian researcher, there is also the problem of researching both in English and in Italian using clearly different keywords. In Italy, like Haines and colleagues (2010) remarked for the United States, researchers are highly collegial, interacting primarily with co-workers in their communities and with colleagues employed in other institutions. They may use e-mail, web sites or face-to-face communication in order to harness relevant information.

Whatever is the working method adopted or the set of actions taken by those who need to build a review of literature on a specific argument, it is clear that more visible is an author and his works, greater it will be the opportunity that he will be identified and cited. Visibility means to be placed at the top in a catalogue query or in the first pages of a search engines interrogation. Understandably, then, authors will strain to ensure that their publications are noticeable and available to as wide a variety of search methods as possible. This can begin with attempting to get articles published in high-profile journals or conferences, but may also include depositing them in institutional or subject repositories, advertising them in listservs and social media, listing them in online curricula vitae and in academic social network sites (Thelwall \& Kousha, 2014). Every web site, in this logic, seems appropriate to increase visibility. Haglund \& Olsson (2008) suggest that to that extent each further site where an author could expose its work is another chance to be found, especially by scholars who do not conduct extensive literature searches or who just use a general search engine.

A specific function is carried out by social network sites (SNSs) that are largely diffused nowadays. Their success depends by the opportunity that they offer to build and nurturing friendships as well as professional relationships. Well-known SNSs posed their achievement on some specific communication or sharing functionality: Facebook emphasises on moods and life scraps, LinkedIn on professional knowledge, Twitter on speedy widespread messages, Instagram on charming pictures, Scribd on documents, SlideShare on slides and presentations. SNSs offer to the users the perception of enhancing life experience, as well as to pursue some kind of accomplishment. Steinfield, Ellison and Lampe (2008), for example, suggest that Facebook affordances help reduce barriers that lower self-esteem students might experience in forming the kinds of large, heterogeneous networks that are sources of bridging social capital. Today, social network sites use is a major activity for Internet users from a wide range of demographic groups. Brenner and Smith (2013) showed that while younger adults are enthusiastic adopters, SNSs continue to grow in popularity for older adults as well: six out of 10 Internet users aged 50-64 are social networking site users, as are $43 \%$ of those aged 65 and older.

\subsection{The role of academic social network sites}

A specific category of SNSs is the academic social networks that provides a new way for scholars to disseminate their publications as well as to provide an innovative way to make researches and to foster the dynamics of informal scholarly communication. The main purpose of these sites is in fact the creation of professional communities, where users can build their social networks by connecting to colleagues, finding old connections and creating new links with researchers relevant to their work. Most of these social networks also aim at increasing personal visibility by creating online profiles and sharing work-related contents (Menendez, De Angeli, \& Menestrina, 2012). In this area, we can identify two main types of instruments: those that were designed for the organisation of research papers, also called reference (or citation) management systems and those that have the primary purpose of providing a showcase for their own publications (Fig. 1). The first kind of products arises from the need to gather and organise citations of books and articles that have been identified across research on archives, web sites, library catalogues and OPACs. They are the heirs of the card catalogues used by generations of students, a set of paper cards containing information such as author, title, year and publisher of consulted works. The first digital product to be developed probably was EndNote (in 1988) followed by RefWorks (in 2001): programs that initially stored their own database on the user's PC. Today, Wikipedia lists 26 different reference management products3, all of them with online functionality. In some cases, they are 'web-based' products; in others, they can be used both online and offline, on different devices,

\footnotetext{
${ }^{3}$ https://en.wikipedia.org/wiki/Comparison_of_reference_management_software
} 
thanks to syncing capabilities between local and remote databases. New features have been added, so that nowadays these tools have become social media platforms that support collaboration and teamwork. Internet, indeed, allows reference management users to work together and share their own resources with others all around the world. Most utilised tools (Zhang, 2012) like Zotero (www.zotero.org), Mendeley (www.mendeley.com) and EndNote (endnote.com) are commonly used to create and join research groups to focus on specific topic4. Each group (private or public, open or closed) can share its own research library, complete with files, bibliographic data, notes, tags and discussion threads. Specific features, moreover, allow users to define their own profile where to place works in order to create opportunity to make themselves known as well as discover other people with similar interests.

The second category of academic social networks sites is mainly oriented to expose researcher works and facilitate the exchange of personal information. These tools provide simple features to describe researchers' institutional information and interests, promote the uploading and sharing of research documents between members, calculate publication analytics and allow users to post public questions to the community. As LinkedIn is used for professional communication and career networking, these systems provide support for scholars and researchers in activities like sharing news, reports, papers and data sets.

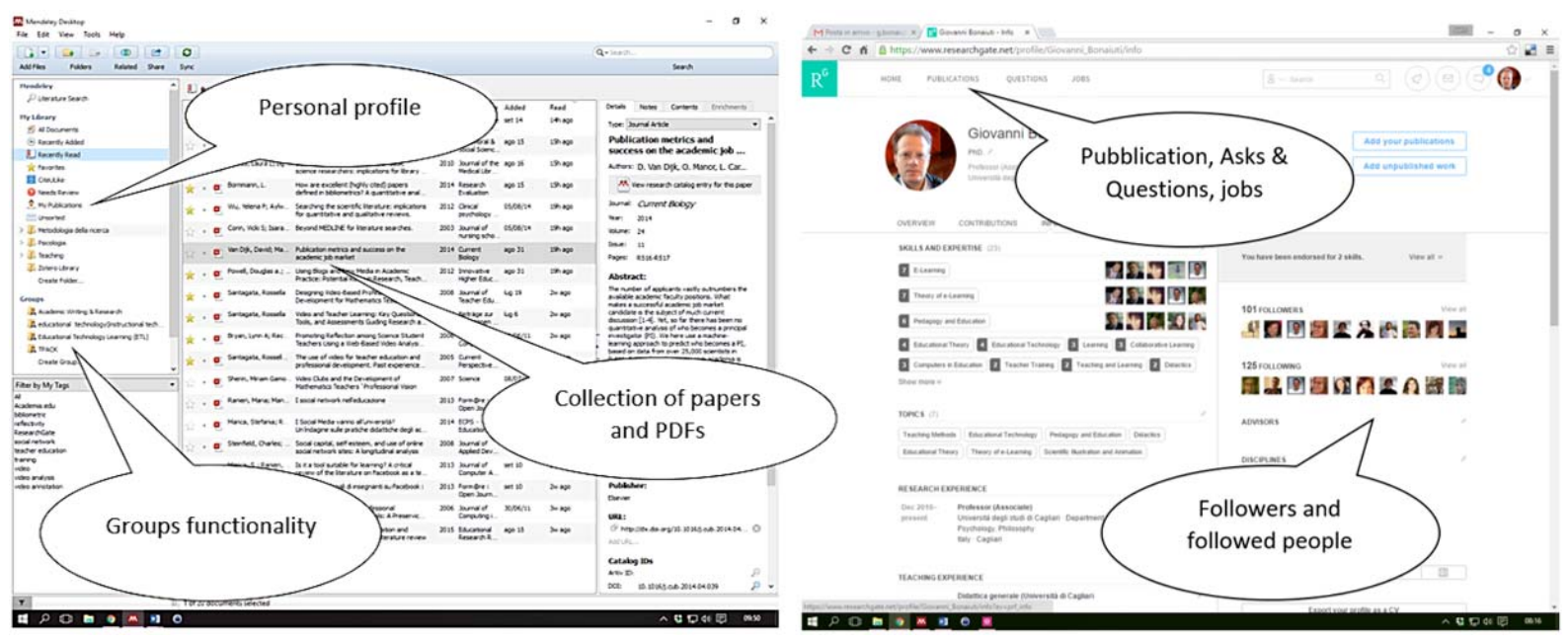

Fig. 1 Mendeley desktop (left) and ResearchGate (right). Two different approaches on academic social networking: based on collection of papers of interest (reference management) or on personal profile and production

A mission that explicitly Academia.edu declares on its web site is 'to accelerate the world's research linking academics each other'. A series of articles (Bullinger, et al., 2010; Huggett, 2010; Menendez, et al., 2012) analyzed size and relative popularity of academic SNSs. In a few years, several of the sites listed are now deceased (e.g. colaboratree, connotea, bioexperts and lalisio), while others have modified their mission. Many of them (e.g. biocrowd labspaces, labroots, and pronetos) focus on life sciences, such as biology and medicine, that are an ideal target for social networks, as they require exchange of complex experimental protocols and expensive datasets (Menendez, De Angeli, \& Menestrina, 2012). Today two major competitors have emerged on the scene (Jordan, 2014): Academia.edu (www.academia.edu) and ResearchGate (www.researchgate.net)5. In these sites, users create profiles, identify collaborators, highlight articles and develop productive research collaborations. While reference management sites focus on readers, helping users to find, collect and share relevant references for their work, Academia.edu and ResearchGate focus more on the producers of research. Both use a 'following model', where users can follow the activity of other users, seeing things like papers added, questions answered and asked, and, in the case of ResearchGate, endorsements from other users. A peculiar function is the ability to crowd-source: individuals post problems or queries on an open forum, relying on the expertise of the community to provide answers and promote an exchange of ideas.

\footnotetext{
${ }^{4}$ Mendeley was acquired in 2013 by Elsevier, the publishing house

${ }^{5}$ Academia.edu, that was founded in 2008 by Richard Price an Oxford University philosopher, has more than 25 million of academics users. ResearchGate, founded in 2008 by physicians Ijad Madisch and Sören Hofmayer, and computer scientist Horst Fickenscher, today has more than 7 million members. GoogleTrends highlights a growing interest in ResearchGate, particularly since Microsoft Corp. co-founder Bill Gates is helping lead a $\$ 35$ million investment. Nevertheless, the two sites are very similar and they have actually eclipsed similar sites like methodspace.com, impactstory.org, iamresearcher.com.
} 
Academic SNSs have a strength point in the repository of publications. Authors can upload printed papers as well as preprints or other documents to their profile. Sophisticated capabilities help researchers in this work by providing links to resources already available in the Internet. Academic SNSs repositories also provide same functionality of self-publishing systems allowing researcher to upload pre-prints, drafts or other documents.

On the bases of their papers, researchers can explore the large network of co-authors, researchers who have been cited or who cited them as well as department colleagues, institution colleagues or other researchers that are followed. The statistics and the scoring about their work are a great encouragement to participate and interact. Both sites have conceived systems to measure scientific impact and provide users with valuable information about their jobs: profile and document views, date and geographic location of readers and so on (both sites regularly e-mails users about this kind of activity, a functionality some members might eventually decide to disable). ResearchGate has conceived an index, called RG Score, to synthesise these analytics that, actually could be considered part of the alt-metrics movement that tracks non-traditional bibliographic metrics. Not only that, but for the fact that they publicise researchers work, these systems make it possible to increase also the traditional metrics.

Lastly, it is important to emphasise that academic SNSs (reference based or 'scholar profile' based) represent an interesting alternative to traditional search tools. It is, in fact, possible to acquire information on the existing literature or on authors more active in a certain sector, asking to researching groups within academic SNSs or making queries in their internal search engine. Sites that combine informal communication and social networking with publicity for scholarly outputs, like academic SNSs, possibly give an advantage to scholars, particularly for younger ones (Thelwall \& Kousha, 2014). They can change methods of doing and communicating researches as well as promote new scholarly reward system and foster web-native scholarship. Despite this, as evidenced by Manca and Ranieri (2014), while studies on the potential of social media for learning are flourishing, investigations about scholars' digital practices are much less common.

\section{Research questions}

Assuming that academic SNSs are interesting tools for researchers (Thelwall \& Kousha, 2014), not much is known about the actual use, particularly, in our country. Furthermore, given the connection that exists between the specific concerns of educational research and the research capability offered by these instruments, this paper aims to investigate the particular use in educational context. Although investigations have been made in our country on the use of social media in education (Ranieri, Manca, \& Fini, 2012; Manca \& Ranieri, 2014), it has not been yet investigated the specific of Academic SNSs. This paper aims to answer the following research questions: How much do Italian scholars use academic SNSs? Which are the most used? Which connections can be done with international research?

\section{Methods}

The work was conducted in two phases: research on international literature and empirical research on data from a group of Italian scholars. The first aimed at identifying the theoretical framework, the second directed at verifying the actual use in a specific context. The first one was carried out using a web-based search engine (Google Scholar) and specialized databases (ERIC, SCOPUS, ScienceDirect). Since the literature research aimed at locating works regarding scholars' use of social networks to improve their visibility, this query was used: ("academic" OR "researcher" OR "scholar" OR "faculty" OR "academic" OR "professor" OR "scientist") AND ("career" OR "bibliometric" OR "altmetric" OR "H-INDEX" OR "G-INDEX" OR "impact factor" OR "tenure" OR "visibility" OR "career") AND ("social network sites" OR "social networking" OR "SNS" OR "Academia.edu" OR "Mendeley" OR "ResearchGate" OR "Zotero"). Each instrument queried returned several hundred results and, in some cases, references from papers retrieved were further investigated. In order to be included in this review, studies had to meet specific inclusion criteria: be written between 2000 and 2015 , address the topic of researchers' use of social media for their career and not, for example, the use that they make for teaching. A total of 65 qualifying studies were included in a Mendeley folder to be used as theoretical framework of the paper. The second phase of the work is addressed to explore uses of academic SNSs achieved by Italian scholars involved in educational research. A list of faculty of Italian 11/D2 SSD (SDS/Scientific Disciplinary Sector extensively titled 'Teaching and learning, special education and educational research') was obtained in July 2015 from MIUR web site (http://cercauniversita.cineca.it/php5/docenti/cerca.php). 11/D2 comprise scholars who deal with educational research as well as educational technology, therefore potentially interested in academic social network tools also as the object of study. The list included 260 scholars, 119 men and 141 women from 51 Italian universities. The list indicates, for each person, sex, university and academic position. In total, there were 27 'fixed-term' researchers, 85 researchers, 97 associate professors, 4 'fixed-term' 


\section{Academic Social Networks: How the web is changing our way to make and communicate researches Bonaiuti}

full professors and 47 full professors. For each subject of the list, the personal profile in Academia.edu, ResearchGate, Mendeley and Zotero was searched. The information retrieved has been codified using the following schema:

- 'Not registered' (he/she does not have a profile);

- 'Registered' (mere registration to the service, he/she has never used it);

- 'Moderate user' (only few information and no papers uploaded);

- 'Advanced user' (well-structured profile with photo, areas of interest and papers).

For scholar coded as advanced user, it has been acquired number of papers uploaded, number of followers and (in ResearchGate only) the RG score.

Afterwards, information regarding the characteristics of scholars' universities using the websites of the Ministry of Education, universities and Research (MIUR) and the National Agency for the Evaluation of the University and Research Systems (ANVUR) has been picked up. In particular, data concerning the nature of universities (private or public), geographic location (north, centre, south and islands of Italy), courses delivery mode (traditional or telematics) and, in relation to the sector $11 / \mathrm{D} 2$, the size of universities (small, medium, large) and the result obtained during the 'VQR 2004/2010' (eValuation of the Quality of Research)6 have been retrieved.

In particular, a ranking of the Italian universities emerges for each disciplinary field from the VQR results. Using the 11/D2 ranking I proceeded to divide universities into quartiles: from the first (worst) to the fourth (best universities) and therefore I aggregate data for researchers.

At the end of the coding work, all this information has been used to identify the presence of correlations between aspects.

\section{Data analysis and findings}

Table 1 shows the results of coding. Mendeley and Zotero are used only by a trifle minority of researchers (less than 3\%) and, therefore, it was decided not to include them in the study. The results are shown broken down for Academia.edu and ResearchGate as well as for either. 'Either' category was elaborated, extrapolating the best value coded in one of the two systems. Indeed, while some researchers use both $(34.94 \%$ coded as 'advanced user'), more often they use only one SNSs $(65.06 \%) 7$. Table 1 shows the results.

Data underline that there is a clear preference, among this group of users, for ResearchGate $(29.23 \%$ of advanced user vs. $13.85 \%$ of Academia.edu), that researchers and associate professors are the main users, and that men are more active than women. Some information is particularly interesting. For example, and contrary to what one might think, temporary scholars (fixed-term researchers and fixed-term full professors) use these systems less than others (see fig. 2). This despite the fact that academic SNSs aim to increase reputation and visibility and hopefully the chance to have their role confirmed or a career development. Further considerations can be made combining these data with those of the institutions of origin. It is possible to notice that there are some considerable differences between groups. For example, it is surprising that scholars of online universities you would think they were more concerned in information and communication technology - pay no attention to this innovation and that scholars from private universities are less engaged in social networking activities than colleagues from public universities (see Fig. 3).

Table 1. Data obtained by consulting ResearchGate and Academia.edu for 11/D2 Scientific Disciplinary Sector.

\begin{tabular}{lrrrrrr}
\hline & \multicolumn{3}{c}{ Frequency } & \multicolumn{3}{c}{ Percentage } \\
\hline & All & Men & Women & All & Men & Women \\
Total of scholars & 260 & 119 & 141 & 100 & 45.77 & 54.23 \\
& Either (one of the two academic social network) & & & \\
Not registered & 136 & 58 & 78 & 52.31 & 48.74 & 55.32 \\
Only registered & 31 & 14 & 17 & 11.92 & 11.76 & 12.06 \\
Moderate use & 10 & 6 & 4 & 3.85 & 5.04 & 2.84
\end{tabular}

\footnotetext{
${ }^{6}$ Data about University characteristics are from "Final GEV and ANVUR reports on VQR 2004-2010" (see: http://www.anvur.org/rapporto/) ${ }^{7}$ Values that are consistent with those of a more extensive research carried out recently in Spain and that shows an overlap of $72 \%$ (Ortega, 2015)
} 
Academic Social Networks: How the web is changing our way to make and communicate researches Bonaiuti

\begin{tabular}{lrrrrrr} 
Advanced use & 83 & 41 & 42 & 31.92 & 34.45 & 29.79 \\
Not registered & ResearchGate & & & & & \\
Only registered & 173 & 77 & 96 & 66.54 & 64.71 & 68.09 \\
Moderate use & 7 & 2 & 5 & 2.69 & 1.68 & 3.55 \\
Advanced use & 4 & 2 & 2 & 1.54 & 1.68 & 1.42 \\
& 76 & 38 & 38 & 29.23 & 31.93 & 26.95 \\
Not registered & Academia.edu & & & & & \\
Only registered & 174 & 75 & 99 & 66.92 & 63.03 & 70.21 \\
Moderate use & 37 & 20 & 17 & 14.23 & 16.81 & 12.06 \\
Advanced use & 13 & 5 & 8 & 5.00 & 4.20 & 5.67 \\
\hline
\end{tabular}

Table 2, which presents data parameterised to the size of each divisions, shows that there are some variability in the use of social network sites by scholars from different universities. The most active researchers seem to be those located in the north of the country and placed in public universities of medium size.

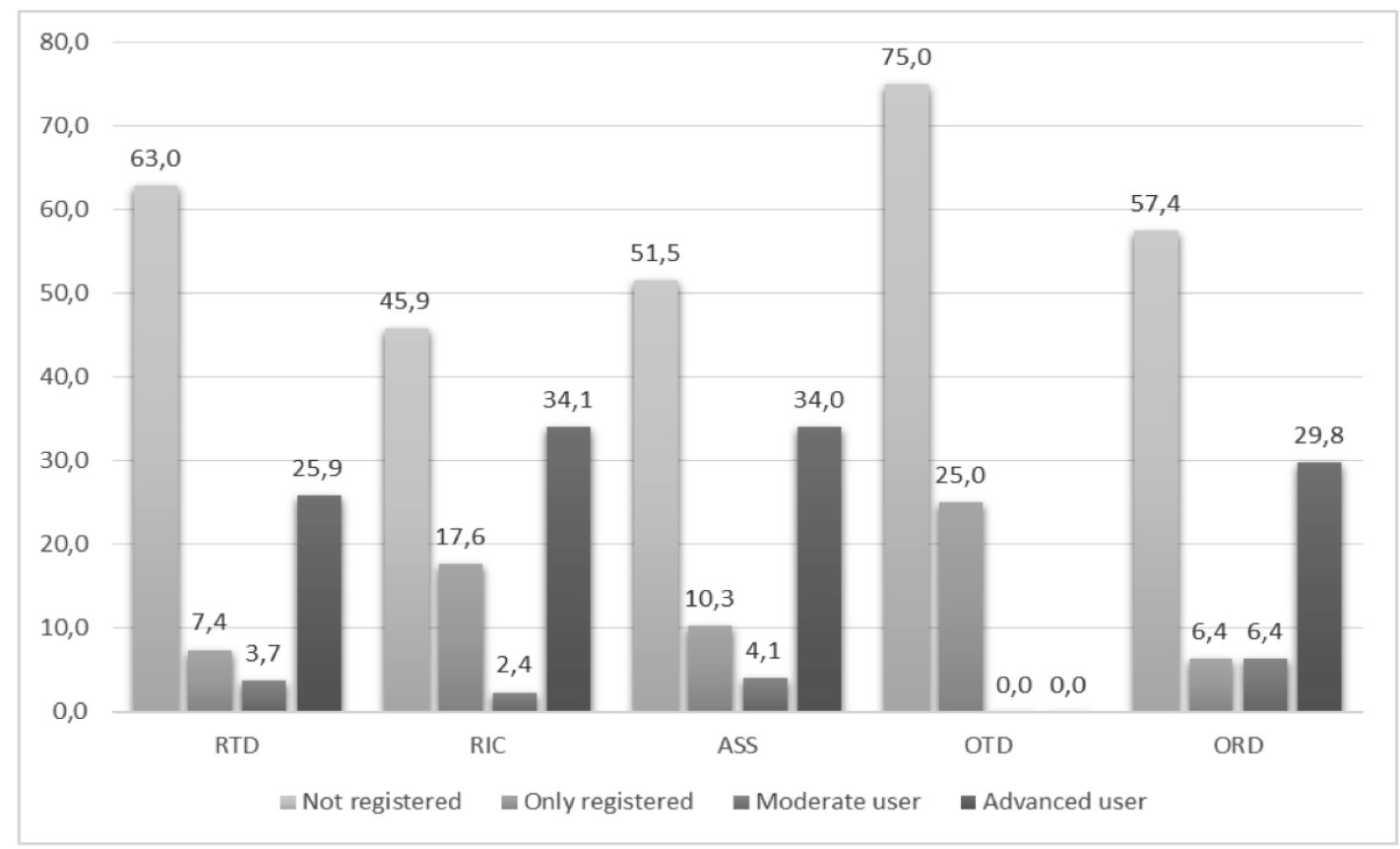

Fig. 2 A-SNSs used by different Faculty groups (data from 'either' site extrapolation). RTD = Fixed-term researchers; RIC = researchers; $\mathrm{ASS}=$ associate professors; OTD = Fixed-term full professors; ORD = Full professors. The data $(\%)$ are related to the size of each group.

Figure 3, which displays only advanced users by type of university, shows that there are some variabilities in the use of social network sites by scholars from different universities. The most active researchers seem to be those located in the north of the country and placed in public universities of medium size. It should be noted that the division into quartiles of universities shows some unpredictable data. Researchers less active are those that work in universities of the first (the worst universities), and the fourth quartile (best universities). Evidently, there is greater dynamism in universities that are outstretched to the improvement. 


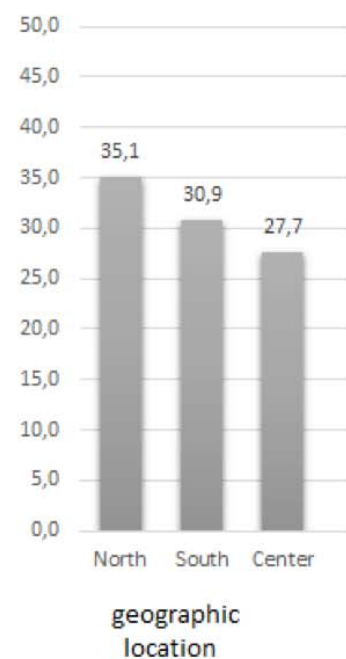

location

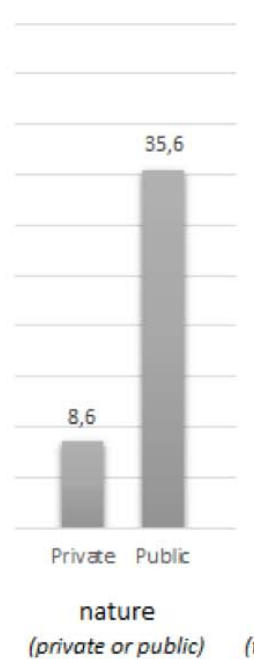

(private or public)

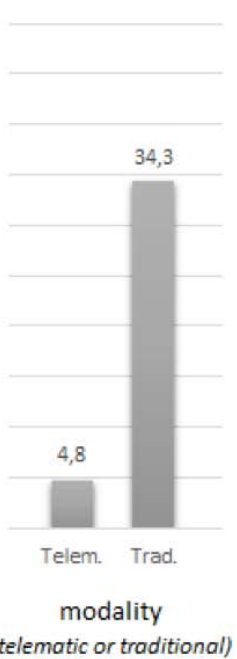

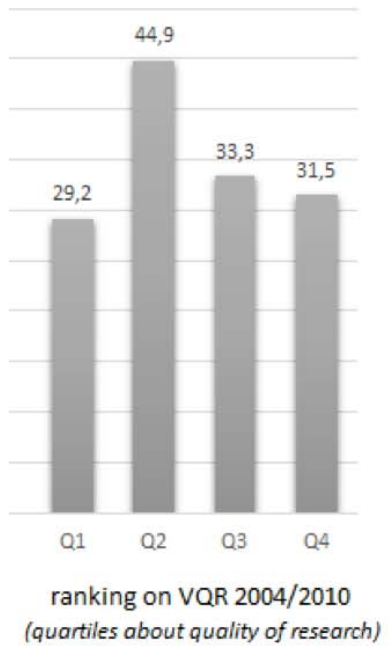

Fig. 3 Analysis of 'advanced user'by type of university.

Values are in percentage and calculated on the basis of proportional weight of each category. Data about users are from "either site" extrapolation (see tab.1); data about University characteristics are from "Final GEV and ANVUR reports on VQR 2004-2010" (see: http://www.anvur.org/rapporto/). The division of universities into quartiles is worked out on the basis of the VQR 2004-2010.

Since it is conceivable that some relationship between elements such as the number of followers, RG score and the academic role, ResearchGate data relating to habitual users groups (Table 2) was used for processing.

Table 2. ResearchGate analytics for habitual users groups (category 'very used'; n=76).

\begin{tabular}{lrrrrrrr}
\hline & \multicolumn{3}{c}{ Followers } & \multicolumn{3}{c}{ RG Score } \\
\hline & N & Total & Mean & SD & Total & Mean & SD \\
Full professor (1) & 12 & 249 & 20.75 & 15.10 & 59.43 & 4.95 & 4.92 \\
Associate professor (2) & 31 & 890 & 28.71 & 21.44 & 148.25 & 4.78 & 4.77 \\
Researcher (3) & 33 & 825 & 25.00 & 35.35 & 137.13 & 4.16 & 6.60 \\
\hline
\end{tabular}

Pearson correlation between the number of followers and RG score shows a moderate positive correlation ( $R$ $=0.626 ; \mathrm{R} 2=0.3919 ; \mathrm{p}<0.00001$ - significant at $\mathrm{p}<0.05$ ). This was predictable since the RG score (an altmetric index that gauges the scholar's strength) is probably sensitive to the consensus that the researcher receive within the community. The correlation between number of followers and academic role8, or between RG score and academic role is very weak and not significant. Moreover, the very high standard deviation denotes an extreme variability in behaviours among individuals. A detailed analysis of the data, in fact, shows behaviours attributable to the specific interests of research, the characteristics of individual character and expectations of each scholar. Scholars more interested in educational technology, for example, are more active in populating and nurturing his or her own profile. Anagraphic data are not available, but empirical considerations based only on age inferable from photographs in the profiles lead us to think that age drive to the SNSs use less than factors like awareness for innovation or interest for new technologies.

\section{Discussion}

Data obtained from our research do not justify any definitive conclusion. The population is small and we are dealing with rapid changes in the development of technological innovation. The spread in the use of social media is growing rapidly worldwide, so data retrieved will be obsolete very quickly. Moreover, it is necessary to take

\footnotetext{
${ }^{8}$ Academic role was calculate considering full professor role (and fixed-term full professor) $=1$, associate professor $=2$, researcher $($ or fixedterm researcher) $=3$.
} 


\section{Academic Social Networks: How the web is changing our way to make and communicate researches Bonaiuti}

into account that Italy, like other non-English-speaking countries, has distinctive behaviours especially in some areas. As exposed by other works (Manca \& Ranieri, 2004) social media remain at the margins of academic life in Italy, particularly in areas of study related to humanities. In this context, many of the relationships occur in physical contexts (e.g. conferences, seminars) and within the traditional social networks (e.g. association meetings). In this perspective, the data reported are somewhat better than expected: $48 \%$ of $11 / \mathrm{D} 2$ Italian Scientific Disciplinary Sector is registered to at least one of the two sites and some 'trailblazer' make advanced use. Overall, as shown by Thelwall and Kousha (2015), our country is pretty active in social networks use. Italy is at the sixth place in the use of ResearchGate for the top 20 countries for total 2013 ISI WoS publications before Germany, United Kingdom and France. This clearly shows that the Italian university system is very dynamic and that, certainly, international standards and practices are providing impulses towards wider dissemination of research output developed in our country9. Various researches have been made in recent years on academic SNSs. Some works point out that, in general, academic SNSs reaffirms rather than extend, established communities (Hoffmann, Lutz, \& Meckel, 2014). Despite the potential for bridging and bonding social capital, the networks have not achieved substantial changes in structures and practices of the academic context or, in other words, that academic SNSs tend to reproduce the same hierarchical structure of physical reality (Menendez, De Angeli, \& Menestrina, 2012). Top influencers, in the academic social networks, are senior scholars with many co-authors ( $\mathrm{Li}, \&$ Gillet, 2013). We have no elements to confirm or deny such hypothesis, but our data show a more fluid situation were full professors are not the most active, nor the most followed. Similarly, the most prestigious universities are not the most attractive. However, all researches (like ours) outline the limits arising from analysing a phenomenon that is recent, multifaceted and changeable. This study, in particular, is limited by the specificity of its target, and by lack of further information about scholars' characteristics (e.g. age, years of experience, productivity and so on), and by the absence of scholars' opinions, thoughts, motivations and concerns. It would be useful to submit a questionnaire to all scholars, but given the characteristics of the population, it would have been difficult to obtain ample responses. Hence, further research should be done to better understand the phenomenon and to explore beliefs, attitudes and expectancy of scholars concerning the innovation in research and their viewpoints on the role of social networks.

\section{Conclusions}

Networking is not only essential for success in academia, but it should also be seen as a natural component of the scholarly profession. Research is typically not a purely individualistic enterprise. While quality of research is important, scholars need to build national and international contacts with their peers to increase visibility, reputation and academic ranking.

This study has attempted to explore the phenomenon of social media platforms and their impact on scholarly practices. By searching for each scholar of 11/D2 scientific field, from the research it has emerged that there are a widespread use of academic SNSs by the scientific community, although it is not easy to identify in detail the reasons whereby some researchers seem to be more active than others. The picture presented shows a realistic insight into the Italian situation, but it is clear that it is a phenomenon in rapid transformation. More precise information, such as age or the academic rankings (i.e. productivity or number of citations received), would be needed for further assumptions and evaluation of possible correlations.

The importance of good quality research is essential for achieving effective outcomes and for advancing the scholars' career. For scholars, publishing their work in leading refereed journals is an increasing expectation in contemporary academia, but as competition growths, the effective communication of their works becomes decisive for visibility. Academic social network sites, as well as other initiatives aimed at creating links and connections between scientific communities, seem to be a strategic and required choice.

\section{References}

Ary, D., Jacobs, L. C., \& Sorensen, Chris. (2009). Introduction to research in education (8th ed.). Belmont, CA: Wadsworth.

\footnotetext{
${ }^{9}$ Further innovation will be expected, also in humanities and in social science, in connection with the changes operated in terms of courses accreditation and researches evaluation (e.g. "VQR" - eValuation of the Quality of Research, "ASN" National Scientific Qualification, "AVA" Self-evaluation, Evaluation and Accreditation).
} 


\section{Academic Social Networks: How the web is changing our way to make and communicate researches}

Bonaiuti

Baynes, G. (2012). Key Issue - Scientometrics, bibliometrics, altmetrics: some introductory advice for the lost and bemused. Insights: The UKSG Journal, 25(3), 311-315. http://doi.org/10.1629/2048-7754.25.3.311

Beall, J. (2012). Predatory publishers are corrupting open access. Nature, 489(7415), 179-179. http://doi.org/10.1038/489179a

Beech, M. (2014). Key Issue How to share and discuss your research successfully online. Insights: The UKSG Journal, 27(1), 92-95. http://doi.org/10.1629/2048-7754.142

Bik, H. M., \& Goldstein, M. C. (2013). An Introduction to Social Media for Scientists. PLoS Biology, 11(4). doi:10.1371/journal.pbio.1001535

Bornmann, L., \& Mutz, R. (2014). Growth rates of modern science: A bibliometric analysis based on the number of publications and cited references. Eprint arxiv:1402.4578. Retrieved from arXiv

Brenner, J., \& Smith, A. (2013). $72 \%$ of Online Adults are Social Networking Site Users groups continue to increase their engagement. Pew Research Center's Internet \& American Life Project, Retrieved from http://www.pewinternet.org/files/oldmedia//Files/Reports/2013/PIP_Social_networking_sites_update_PDF.pdf

Bullinger, A. C., Hallerstede, S. H., Renken, U., Söldner, J.-H., \& Möslein, K. M. (2010). Towards Research Collaboration - a Taxonomy of Social Research Network Sites. In Proceedings of the Sixteenth Americas Conference on Information Systems, Lima, Peru, August 12-15, 2010 (pp. 1-9). Lima, Peru.

Falagas M.E., Pitsouni E.I., Malietzis G.A., \& Pappas G. (2008). Comparison of PubMed, Scopus, Web of Science, and Google Scholar: strengths and weaknesses. FASEB Journal, 22(2), pp. 338-42.

Galligan, F., \& Dyas-Correia, S. (2013). Altmetrics: Rethinking the Way We Measure. Serials Review, 39(1), 56-61. doi:10.1016/j.serrev.2013.01.003

Greenhow, C., \& Gleason, B. (2014). Social scholarship: Reconsidering scholarly practices in the age of social media. British Journal of Educational Technology, 45(3), 392-402.

Haglund, L., \& Olsson, P. (2008). The impact on university libraries of changes in information behavior among academic researchers: A multiple case study. The Journal of Academic Librarianship, 34(1), 52-59.

Haines, L. L., Light, J., O’Malley, D., \& Delwiche, F. a. (2010). Information-seeking behavior of basic science researchers: implications for library services. Journal of the Medical Library Association : JMLA, 98(1), 73-81. http://doi.org/10.3163/1536-5050.98.1.019

Happell, B., \& Cleary, M. (2013). Research career development: The importance of establishing a solid track record in nursing academia. Collegian, 21(3), 233-238. http://doi.org/10.1016/j.colegn.2013.04.005

Hoffmann, C. P., Lutz, C., \& Meckel, M. (2014). Impact Factor 2.0: Applying Social Network Analysis to Scientific Impact Assessment. In Proceedings of the 47th Hawaii International Conference on System Sciences (pp. 1576-1586). doi:10.1109/HICSS.2014.202

Hugget, S. (2010). Social networking in academia. Research Trends, 16(March), 5-6.

Hugget, S. (2010). Social networking in academia. Research Trends, 16(March), 5-6.

Jordan, K. (2014). Academics and their online networks: Exploring the role of academic social networking sites. First Monday, 19(11), 1-19.

Kinal, J., \& Rykiel, Z. (2013). Open Access as a Factor of Enhancing of the Global Information Flow. Procedia - Social and Behavioral Sciences, 83, 156-160. http://doi.org/10.1016/j.sbspro.2013.06.030 


\section{Academic Social Networks: How the web is changing our way to make and communicate researches Bonaiuti}

Kortelainen, T., \& Katvala, M. (2012). “Everything is plentiful-Except attention” Attention data of scientific journals on social web tools. Journal of Informetrics, 6(4), 661-668. doi:10.1016/j.joi.2012.06.004

Labrie, N., Amati, R., Camerini, A.-L., Zampa, M., \& Zanini, C. (2015). “What's in it for us?” Six dyadic networking strategies in academia. Studies in Communication Sciences, 15(1), 158-160. http://doi.org/10.1016/j.scoms.2015.03.012

Li, N., \& Gillet, D. (2013). Identifying influential scholars in academic social media platforms. In Proceedings of the 2013 IEEE/ACM International Conference on Advances in Social Networks Analysis and Mining ASONAM '13 (pp. 608-614). Niagara, Ontario, CAN: ACM. doi:10.1145/2492517.2492614

Liu, J., \& Adie, E. (2013). New perspectives on article-level metrics: developing ways to assess research uptake and impact online. Insights the UKSG Journal, 26(July), 153-158. doi:10.1629/2048-7754.79

Lupton, D. (2014). 'Feeling Better Connected': Academics' Use of Social Media. Canberra: News \& Media Research Centre, University of Canberra.

Mabe, M. A. (2010). Scholarly Communication: A Long View. New Review of Academic Librarianship, 16(sup1), 132-144. doi:10.1080/13614533.2010.512242

Manca, S., \& Ranieri, M. (2014). I Social Media vanno all'università? Un'indagine sulle pratiche didattiche degli accademici italiani. ECPS - Educational, Cultural and Psychological Studies, (10), 305-339. doi:10.7358/ecps-2014-010-manc

Marino, W. (2012). Fore-cite: tactics for evaluating citation management tools. Reference Services Review, 40(2), 295-310. http://doi.org/10.1108/00907321211228336

Menendez, M., De Angeli, A., \& Menestrina, Z. (2012). Exploring the virtual space of academia. In From Research to Practice in the Design of Cooperative Systems: Results and Open Challenges. Proceedings of the 10th International Conference on the Design of Cooperative Systems, COOP 2012 (pp. 49-63). Marseille, France. doi:10.1007/978-1-4471-4093-1 4

Moed, H.F. (2005). Citation analysis in research evaluation. New York: Springer

Mohammadi, E., \& Thelwall, M. (2014). Mendeley readership altmetrics for the social sciences and humanities: Research evaluation and knowledge flows. Journal of the Association for Information Science and Technology, 65(8), 1627-1638. doi:10.1002/asi.23071

Niu, X., Hemminger, B. M., Lown, C., Adams, S., Brown, C., Level, A., ... Cataldo, T. (2010). National study of information seeking behavior of academic researchers in the United States. Journal of the American Society for Information Science and Technology, 61(5), 869-890. http://doi.org/10.1002/asi.21307

Ortega, J. L. (2015). Relationship between altmetric and bibliometric indicators across academic social sites : The case of CSIC's members. Journal of Informetrics, 9(1), 39-49. http://doi.org/10.1016/j.joi.2014.11.004

Ovadia, S. (2014). ResearchGate and Academia.edu : Academic Social Networks. Behavioral \& Social Sciences Librarian, 33(3), 165-16941. http://doi.org/10.1080/01639269.2014.934093

Powell, D. a., Jacob, C. J., \& Chapman, B. J. (2012). Using Blogs and New Media in Academic Practice: Potential Roles in Research, Teaching, Learning, and Extension. Innovative Higher Education, 37(4), 271282. doi:10.1007/s10755-011-9207-7

Ranieri, M., Manca, S., \& Fini, A. (2012). Why (and how) do teachers engage in social networks? An exploratory study of professional use of Facebook and its implications for lifelong learning. British Journal of Educational Technology, 43(5), 754-769. doi:10.1111/j.1467-8535.2012.01356.x 
Salem, J., \& Fehrmann, P. (2013). Bibliographic Management Software : A Focus Group Study of the Preferences and Practices of Undergraduate Students Bibliographic Management Software : A Focus Group Study of the Preferences and Practices of Undergraduate Students. Public Services Quarterly, 9(October), 110-120. http://doi.org/10.1080/15228959.2013.785878

Steinfield, C., Ellison, N. B., \& Lampe, C. (2008). Social capital, self-esteem, and use of online social network sites: A longitudinal analysis. Journal of Applied Developmental Psychology, 29(6), 434-445. doi:10.1016/j.appdev.2008.07.002

Tapscott D., Williams A. D. (2007). Wikinomics 2.0: La collaborazione di massa che sta cambiando il mondo, Milano: Etas Libri.

Thelwall, M., \& Kousha, K. (2014). Academia.edu: Social network or academic network. Journal of the Association for Information Science and Technology, 65(4), 721-731. doi:10.1002/asi.23038

Thelwall, M., \& Kousha, K. (2015). ResearchGate: Disseminating, communicating, and measuring Scholarship? Journal of the Association for Information Science and Technology, 66(4), 876-889. doi:10.1002/asi.23236

Van Eperen, L., \& Marincola, F. M. (2011). How scientists use social media to communicate their research. Journal of Translational Medicine, 9(1), 199. doi:10.1186/1479-5876-9-199

Walters W.H. (2011). Comparative Recall and Precision of Simple and Expert Searches in Google Scholar and Eight Other Databases. Portal: Libraries and the Academy, 11(4), pp. 971-1006.

Weller, M. (2011). The Digital Scholar. How technology is transforming scholarly practice. London: Bloomsbury.

Yang, S., Qiu, J., \& Xiong, Z. (2010). An empirical study on the utilization of web academic resources in humanities and social sciences based on web citations. Scientometrics, 84(1), 1-19. http://doi.org/10.1007/s11192-009-0142-7

Zhang, Y. (2012). Comparison of Select Reference Management Tools. Medical Reference Services Quarterly, 31(1), 45-60. http://doi.org/10.1080/02763869.2012.641841 